\title{
CULTURA E MEMÓRIA EM PERSPECTIVA: REFLEXÕES SOBRE OS ACERVOS HISTÓRICO-CULTURAIS NO MUNICÍPIO DE SÃO BORJA-RS
}

\author{
CULTURE AND MEMORY IN PERSPECTIVE: REFLECTIONS ON HISTORICAL AND CULTURAL \\ COLLECTIONS IN THE CITY OF SÃO BORJA-RS
}

\section{Larissa Conceição dos Santos' ${ }^{1}$ Anna Clara Pereira Machado², Catarina Maria Amorim³}

RECEBIDO EM: 25/07/2020 | ACEITO EM: 15/09/2020

DOI: $10.5902 / 2317175848364$

\section{RESUMO}

O presente trabalho tem por objetivo apresentar os resultados preliminares do projeto de pesquisa Memória Pública e Memória Cultural: um estudo histórico comunicacional, no que diz respeito à problemática do registro, conservação e acesso aos acervos histórico-culturais no município de São Borja-RS. Em sua primeira fase a pesquisa buscou realizar análises em Atos, decretos e leis ordinárias municipais relacionadas às políticas culturais do município. Posteriormente, diante da dificuldade de acesso aos materiais, descaso e evidente falta de conservação arquivística ampliou-se o escopo da pesquisa para a conservação da memória, especificamente da memória pública e cultural. O estudo fundamenta-se teoricamente na abordagem da Semiótica cultural (LOTMAN, 1998) e desenvolve-se metodologicamente a partir de pesquisa exploratória de campo, entrevistas exploratórias e pesquisa bibliográfica com base em dados primários e secundários. Apresentam-se aqui os resultados preliminares referentes ao levantamento inicial sobre os acervos histórico-culturais existentes no município de São Borja, bem como as possibilidades e limitações para a sua preservação.

Palavras-chave: Memória; cultura; acervo; semiótica cultural; preservação histórica.

\footnotetext{
1 Doutora em Sciences de l'Information et de la Communication (PARIS-SORBONNE). Doutora em Ciências da Comunicação (ECA-USP). Professora Adjunta - Universidade Federal do Pampa (UNIPAMPA). Grupo de Pesquisa t3xto - UNIPAMPACNPq Laboratoire GRIPIC -CELSA/PARIS-SORBONNE

ORCID iD: https://orcid.org/0000-0002-1834-5547. Lattes: https://orcid.org/0000-0002-1834-5547

Universidade Federal do Pampa - UNIPAMPA. Brasil

2 Pesquisadora de iniciação científica (PROBIC- FAPERGS) no Projeto de Pesquisa Memória Pública e Memória cultural: um estudo histórico-comunicacional. Discente do Curso de Relações Públicas da UNIPAMPA e integrante do Grupo de Pesquisa t3xto (UNIPAMPA). Lattes: http://lattes.cnpq.br/0379490163718442. Universidade Federal do Pampa (UNIPAMPA). Grupo de Pesquisa t3xto - UNIPAMPAVNPq. Brasil

3 Pesquisadora de iniciação científica (PIBIC- CNPq) no Projeto de Pesquisa Memória Pública e Memória cultural: um estudo histórico-comunicacional. Discente do Curso de Publicidade e Propaganda da UNIPAMPA e integrante do Grupo de Pesquisa t3xto (UNIPAMPA). Lattes: http://lattes.cnpq.br/3984775254481670. Universidade Federal do Pampa (UNIPAMPA). Grupo de Pesquisa t3xto - UNIPAMPAVCNPq. Brasil
} 
CULTURA E MEMÓRIA EM PERSPECTIVA:

REFLEXÕES SOBRE OS ACERVOS HISTÓRICO-CULTURAIS NO MUNICÍPIO DE SÃO BORJA-RS

\begin{abstract}
This paper aims to present the preliminary results of the research project Public Memory and Cultural Memory: a historical communication study, with regard to the issue of registration, conservation and access to historical and cultural collections in the municipality of São Borja-RS. In its first phase the research sought to carry out analyzes in Acts, decrees and ordinary municipal laws related to the cultural policies of the municipality. Subsequently, given the difficulty in accessing the materials, neglect and an evident lack of archival conservation, the scope of research for the conservation of memory was broadened, specifically of public and cultural memory. The study is theoretically based on the approach of cultural Semiotics (LOTMAN, 1998) and develops methodologically from exploratory field research, exploratory interviews and bibliographic research based on primary and secondary data. Preliminary results referring to the initial survey on the historical and cultural collections in the municipality of São Borja are presented here, as well as the possibilities and limitations for their preservation.
\end{abstract}

Keywords: Memory; culture; collection; cultural semiotics; historical conservation.

\title{
1 Introdução
}

O que difere os seres humanos dos demais animais são nossas habilidades de atribuir significados às coisas. Partindo desse ponto de vista, percebemos que parte da nossa identidade é desenvolvida pelas significações que atribuímos, gerando um sentido, seja por meios materiais reais ou simbólicos. Está percepção vai de acordo com alguns autores da antropologia (Geertz, 1989) e da comunicação (Lotman, 1998), principalmente ao atrelar essa ideia como uma concepção de cultura. Geertz (1989) defende esse pensamento ao dissertar sobre cultura num sentido semiótico. Lotman (1998) discorre dentro dos estudos da disciplina teórica dos estudos russos, Departamento de Semiótica da Universidade de Tártu-Moscou, Estônia, à semiótica da cultura. De certo modo em ambas as áreas os autores consideram cultura como um conjunto de sistemas de signos.

Para além disso, ao entendermos cultura nesse sentido, Lotman (1998) nos diz que cultura se dirige contra o esquecimento, visto que esta trabalha com a ideia de memória coletiva, ao ser preservado. Ainda dialogando com os pensamentos do autor, ao compreendermos cultura como algo que recebe as informações e as codifica entendemos que cultura são textos que, ao serem interpretados, criam uma teia de significados na qual podem ser considerados a um longo período ou não, e desse modo que cultura se dirige contra o esquecimento, sendo um meio de memória coletiva.

Nessa direção, se de acordo com Machado (2010) a cultura é um centro produtor de textos, como fruto de semiose da própria natureza, ela se torna um mecanismo que transforma a informação em texto e assim, o texto da cultura não resulta em um único código. Logo, os textos desenvolvem tarefas para funcionamento da cultura, tendo uma função comunicativa, transitando 
significados; uma função de formação de sentidos; e uma função de memória da cultura, no qual se introduz na história intelectual da humanidade, com vista a regular comportamentos. Portanto ao facilitar o acesso aos documentos presentes nos acervos municipais, é um meio de preservar a memória presente na cultura São-borjense, não a levando ao esquecimento, dando continuidade aos significados já produzidos e oportunizando a geração de novos sentidos.

Tendo como pano de fundo as perspectivas teóricas acima apresentadas, nosso artigo tem por finalidade apresentar os resultados preliminares do Projeto de Pesquisa "Memória Pública e Memória Cultural: um estudo histórico comunicacional" ${ }^{3}$, que tem por foco aqui a pesquisa exploratória inicial sobre as fontes históricas - centros de documentação, arquivos e acervos - existentes no município de São Borja - RS e as possibilidades e limitações no que diz respeito à preservação da memória pública e cultural.

Para tanto, foram realizados levantamentos e análises de Atos, decretos e leis ordinárias municipais a partir de pesquisa documental nos acervos públicos da cidade, além de visitas e entrevistas exploratórias entre 2018 e 2019 que puderam dar uma dimensão da variedade de documentação histórica existente no município (SANTOS; FERNANDES, 2020). A partir de então o projeto visa integrar e compreender, de maneira mais ampla, a problemática da conservação da memória, especificamente da memória pública e cultural sob a ótica da semiótica da cultura (LOTMAN, 1998) e da comunicação.

Nesse sentido, apresenta-se aqui as contribuições da Escola de Tartú-Moscou para o estudo da cultura e da memória, bem como os levantamentos iniciais acerca do acervos e arquivos existentes em São Borja, em termos de objetos formas de preservação destes espaços, resultantes de pesquisa exploratória iniciada em 2018 junto ao Arquivo Público Municipal, Memorial Casa João Goulart, Museu Getúlio Vargas, Museu Ergológico da Estância - Os Angueras, Museu Municipal Appariccio Silva Rillo e Arquivo da Câmara Municipal de Vereadores de São Borja. A pesquisa se justifica a partir da dificuldade de acesso e sistematização dos dados relativos à cultura no município, e os desafios observados para a conservação desse patrimônio.

\section{Referencial teórico}

\subsection{Cultura e memória pela ótica da Escola de Tartú-Moscou}

Nas ciências sociais buscamos entender a cultura e seus significados, embora nem sempre se chegue a um consenso em relação às concepções. Segundo Thompson (1985, p. 165) "muitos analistas concordam que os estudos dos fenômenos culturais são uma preocupação de importância central para as ciências sociais como o todo". Na área da comunicação, as investigações da antropologia tornam-se algumas das principais fontes ao estudo da cultura. Sul - FAPERGS e do Conselho Nacional de Desenvolvimento Científico e Tecnológico - CNPq. 
No entanto, a Escola de Tártu-Moscou, fundada nos anos 60 na Rússia, no centro de estudos semióticos e linguísticos, dá origem a uma disciplina teórica entre os estudos russos que buscou estabelecer a cultura como um conjunto de sistemas semióticos. Em conformidade com Ferreira (1994), cultura é um mecanismo organizado, complexo, que conserva as informações. Desse modo, a autora conceitualiza cultura de acordo com a tese de luri Lotman, um dos autores pioneiros da semiótica russa. Para além disso, os autores abordam cultura como um meio de penetração, que possui relação dos signos aos signos e aos sistemas de signos. Assim, "cultura recebe as coisas novas, codifica e decodifica mensagens, traduzindo-as a um outro sistema de signos" (FERREIRA, 1994, p. 116).

Nesse sentido, cultura é o feixe de sistema semióticos, em relação às linguagens, no qual organiza as informações recebidas. De acordo com Ferreira (1994, p. 117) "traduzir um certo setor da realidade em linguagem, transformá-lo num texto, isto é, numa informação codificada de um certo modo, esta informação na memória coletiva é fundamental". A partir dessa perspectiva, cultura passa a ser utilizada contra o esquecimento, sendo ele um mecanismo de memória, coincidindo com a existência de algo. Assim, cultura é memória, a qual está expressa num sistema de interpretações e prescrições. Dessa forma, ainda em conformidade com a autora, toda cultura se cria conforme sua própria existência, dando continuidade à própria memória.

Por outro lado, significa também dizer que passa a ser uma espécie de signos organizados, que segundo Lotman (1998, p. 8), "na história real da cultura, encontramo-nos em mais de uma ocasião com episódios na qual no surgimento do texto precede o surgimento da linguagem e estimula a última fase". Na esteira do pensamento lotmaniano, Ferreira (1994) afirma que a origem da história e antes do mito como consciência é uma memória coletiva. Assim compreendemos que se cultura é um sistema de signos, são textos que geram novos significados, mas mais que isso, é um modo de fixar a memória cultural. Desse modo a preservação é um meio de guardar a cultura e acumular memória. Nesse sentido, é importante abordar a semiótica da cultura, como transformação da informação recebida em informações codificadas, os textos. De acordo com Machado (2010), cultura é elemento de produção, é a transformação da informação percebido em texto, sendo ele fruto da semiose, sendo esse texto não resultado de um único código (AMORIM; SANTOS, 2020).

Para Lotman (1998, p. 09) "o texto introduzido desde o exterior estimula e conecta a consciência. Mas para que esta "conexão" aconteça, o dispositivo que é conectado deve ter fixado na sua memória uma experiência semiótica". Logo, a semiótica da cultura possui relação com o conceito de cultura simbólica, citada por Thompson (1985), e conceitualizada por Geertz (1989) no qual cultura são os significados atribuídos às coisas. Para além disso, ambos os conceitos dialogam, quando trabalham a cultura como textos, sendo assim cultura são interpretações intimamente ligadas à consciência e à memória. 
Sob esse viés, Lotman procurou estabelecer a cultura como um conjunto de sistemas semióticos, um sistema de signos que utilizam códigos, dando origem a várias expressões humanas. Diante disso, cultura é um mecanismo organizado e complexo, que conserva as informações, conforme a tese de Lotman (1975) e mais tarde aos estudos dedicados por Ferreira (1994). Podemos estabelecer, a partir do exposto, uma semelhança no conceito de cultura contextualizado por Lotman e Geertz, no qual ambos os teóricos, este da antropologia, aquele da linguística, baseiam-se da concepção de que o ser humano possui habilidades de atribuir significados às coisas, sejam elas reais ou simbólicas.

A pesquisadora Ana Paula Velho aduz que cultura "é um sistema de armazenamento, processamento e transferência de informação" e que, para além disso, "utiliza-se códigos inerentes à própria cultura, grandes signos convencionais, que organizados dão sentido às diferentes expressões dos grupos sociais" (VELHO, 2009, p. 253).

À vista disso, na atualidade, em que os indivíduos estão acostumados com os meios de comunicação digital e novos avanços tecnológicos, preservar a memória em espaços físicos, como acervos e patrimônios, torna-se um grande desafio, tendo em vista que "a preservação destes bem vem encontrando dificuldades de conservação face à escassez de recursos e a falta de vontade política para sua efetivação" (BEZERRA; OLIVEIRA, 2013, p. 05).

Contudo, com todos os avanços nos meios de comunicação e tecnologia, essas problemáticas em relação aos acervos e patrimônios culturais podem ser solucionadas. Os novos meios de comunicação digitais podem moldar a maneira como a memória e, consequentemente, a cultura pode ser preservada. Conforme Santos e Bonito (2009):

Se antes a formação da memória limitava-se ao pensamento humano, expresso pela narração, pela oralidade, com escrita, as possibilidades de comunicação são ampliadas; mas recentemente com digital, as barreiras do tempo e do espaço são ultrapassadas, e o registro informacional e memorial é alterado, mediante o suporte virtual e a capacidade ilimitada oferecidas pela web (SANTOS; BONITO, 2019, p. 235).

Nesse sentido, se na atualidade os textos escritos ou orais, arquivados em livros, cadernos etc, correm o risco de serem perdidos, devido aos cuidados incorretos com os materiais perecíveis, visto que de acordo com Bezerra e Oliveira (2013), esses materiais são naturalmente afetados pelas variações da umidade e da temperatura, sendo deteriorados conforme o tempo. Com os novos meios de comunicação, como ferramenta de preservação, a restauração através de sites e blogs pode resgatar a memória e, para além disso, preservar a cultura, sem o risco de serem danificados.

Desse modo, os avanços tecnológicos que têm ocorrido são fundamentais à cultura, que são interpretações conectadas à consciência e à memória. De acordo com Machado (2010), a cultura como fruto da semiose é um ele- 
mento de produção, é a transformação da informação percebida em texto, que não são resultados apenas de um código. Conforme Lotman (1998) "o texto introduzido desde o exterior estimula e conecta a consciência. Mas para que esta "conexão" aconteça, o dispositivo que é conectado deve ter fixado na sua memória uma experiência semiótica" (LOTMAN, 1998, p. 09).

Assim, a cultura é um sistema semiótico, textos que geram interpretações, de interpretações, relacionadas à consciência. Diante disso, ao ser preservada, as gerações futuras poderão compreender o contexto social e cultural no qual estão inseridas. E com os novos meios de comunicação que surgiram e os avanços tecnológicos, a preservação da memória se torna ampla. Em conformidade, Santos e Bonito (2019) "com advento das tecnologias de informações digitais, os acervos e patrimônios históricos, materiais ou imateriais passam a compor a memória digital, disponível e acessível através de suportes eletrônicos como a web" (SANTOS; BONITO, 2019. p. 235).

Como podemos inferir, ao adequar os acervos para os novos formatos, disponibilizando-os em formatos digitais, há uma contribuição à cultura, possibilitando a ressignificação ou criação de novos significados, a partir de signos já existentes. Vale ressaltar que com os novos meios de comunicação não significa que se deva substituir os acervos físicos pelo digital, mas sim fazer uso dessas novas tecnologias para restaurar e disponibilizar os documentos para acesso. Para além disso, assim como a humanidade evolui, em relação aos novos meios de comunicação e tecnologias, os patrimônios e acervos também deverão se adaptar às mudanças, ressignificando-se no digital.

No projeto Memória Pública e cultural a abordagem da semiótica cultural serve como fundamentação teórica adequada para a investigação da problemática relacionada à preservação cultural e memorial em uma região de forte valor histórico-cultural, como o oeste missioneiro. Através de uma perspectiva histórica e comunicacional, busca-se investigar e compreender, de maneira mais ampla, a problemática da conservação da memória cultural e pública do município de São Borja-RS, tendo como objeto de estudo os dispositivos públicos municipais que deveriam contribuir a essa salvaguarda - arquivos, acervos, memoriais, entre outros.

Para isso, explora-se a seguir os contornos teóricos relacionados à formação de espaços de registro e preservação de objetos de valor histórico, como os centros de memória e documentação, a constituição de acervos e arquivos, para, finalmente, apresentar o panorama e potencial documental com o qual nos deparamos atualmente no município de São Borja.

\subsection{Centros de memória, acervos e arquivos: uma breve conceituação}

Ao tratar-se de centros memórias, compreendemos que são lugares onde se é armazenado os mais diversos tipos de registros, para assim poder realizar estudos e dessa forma entender e conhecer sobre o passado. 
De acordo com Lauretti (2011), os centros de documentação configuram-se como espaços híbridos, pois suas características e seus acervos poderiam tanto fazer parte de bibliotecas quanto de arquivos de museus, sendo que a informação se constitui como seu objeto central, à frente inclusive dos próprios documentos físicos, podendo funcionar como bases de dados.

As denominações desse tipo de serviço de informação podem variar de "Centro de documentação e memória " até Centro de memória " etc., mas geralmente os acervos são similares entre si, podendo conter documentos audiovisuais, bibliográficos, objetos museológicos, fotografias, documentos empresariais e depoimentos em áudio ou vídeo (LAURETTI, 2011, p. 8).

A fim de ilustrar as semelhanças, diferenças e particularidades destes organismos que muitas vezes se confundem, a pesquisadora elabora um quadro comparando os centros de memória, centros de documentação e arquivos históricos, com relação aos seus objetivos, a constituição de seus acervos e, ainda, o público-alvo para o qual se direcionam, conforme pode ser observado no Quadro 1.

Quadro 1 - Comparação entre espaços de preservação documental e memorial

\begin{tabular}{|l|l|l|l|}
\hline & Centro de documentação & Centro de memória & Arquivo histórico \\
\hline Objetivos & $\begin{array}{l}\text { Reunir informação especializada } \\
\text { em um assunto }\end{array}$ & $\begin{array}{l}\text { Reunir informação a respeito de uma } \\
\text { instituição / um assunto }\end{array}$ & $\begin{array}{l}\text { Reunir documentos produzidos por } \\
\text { uma instituição }\end{array}$ \\
\hline Acervo & $\begin{array}{l}\text { Documentação gerada por } \\
\text { instituições } \\
\text { Coleções } \\
\text { Exemplares únicos ou múltiplos }\end{array}$ & $\begin{array}{l}\text { Documentação gerada pela instituição } \\
\text { Coleções } \\
\text { Exemplares únicos ou múltiplos }\end{array}$ & $\begin{array}{l}\text { Documentação gerada pela } \\
\text { instituição } \\
\text { Únicos exemplares }\end{array}$ \\
\hline Público-alvo & Pesquisadores & $\begin{array}{l}\text { Público interno e pesquisadores } \\
\text { externos }\end{array}$ & Pesquisadores e grande público \\
\hline
\end{tabular}

Parece ser um consenso entre os autores (TOTINI; GAGETE, 2004; LAURETTI, 2011, CAMARGO; GOULART, 2015) que a constituição dos chamados "Centros de Memória" está ligada à prática empresarial, criados como forma de atender uma necessidade institucional, respondendo "a uma demanda por informações relativa à sua trajetória e origem, seus principais objetivos são a preservação de documentos, o atendimento a pesquisas internas e externas e gerar produtos e serviços sobre a trajetória histórica da empresa" (COSTA; VITORIANO, 2018, p. 527).

Como as denominações são muitas, e, frequentemente, dão conta de um processo de organização documental e histórica mais ampla, Centros de memória e de documentação na atualidade possuem acervos heterogêneos, diversificados, compostos por documentos dos mais variados tipos - textuais, sonoros, audiovisuais etc. - funcionando como um grande espaço de conservação e organização documental e da memória de uma organização, seja ela pública, privada ou sem fins lucrativos.

Em uma dimensão epistemológica, Camargo e Goulart (2015) trazem 
CULTURA E MEMÓRIA EM PERSPECTIVA:

para o debate um dado do cenário nacional, um momento em que organizações iniciam um movimento de valorização de suas memórias. Tomamos como exemplo os dados publicados segundo as autoras, que nos relata que "A partir dos anos 1980 começam a surgir, no Brasil, os centros de memória, ligados a organizações públicas e privadas e também àquelas sem finalidade lucrativa, chamadas de terceiro setor" (CAMARGO; GOULART, 2015, p. 63).

Ou seja, se estas organizações iniciaram o movimento de preocuparem-se em salvaguardar suas memórias e recontar sua trajetória para seus clientes, ou público interessado, quanto mais uma cidade que teve no cenário político nacional dois presidentes, deveria interessar-se em fazer o mesmo por todos acervos, ainda não regulamentados. E isto deveria ocorrer partindo de um amontoado de documentos para um local oficial, com informações sistematizadas e disponível ao alcance da população ou demais interessados.

Cabe também enfatizar o caso dos inúmeros acervos em mãos de particulares, os quais são detentores da história de personagens importantes na história do município de São Borja, como por exemplo do Grupo Amador de Arte, Os Angueras e seus fundadores, Apparício e Suzy Rillo, Carlos e Maria Moreno, José e Magda Bicca, Sady Santiago e sua noiva Ana Rosa, Darwey e Mariazinha Orengo, Telmo de Lima Freitas e Vicente Goulart. Estes, são peças fundamentais na preservação da história e memória da música e da cultura local.

Segundo as autoras "a legislação brasileira admite a possibilidade de considerar de interesse público e social os arquivos de determinadas pessoas jurídicas de direito privado ${ }^{4}$, mas são poucas as iniciativas do estado no sentido de assumir sua custódia" (CAMARGO; GOULART, 2015, p.64), ou seja, há embasamento legal para que os acervos particulares, compositores da história local passem a ser de visitação ao público, seja para pesquisas ou aberto a visitações.

As autoras destacam a relevância em preservar a memória local, pois "modismo ou não, o fato é que os centros de memórias passaram a ser alvo de clubes esportivos, universidades, escolas, igrejas, partidos políticos e sindicatos, entre outras entidades" (CAMARGO; GOULART, 2015, p.65). Entende-se, portanto, que as instituições passam a perceber a importância da criação e manutenção dos acervos históricos, abordados de inúmeras formas através de exposições, de museus, ou ainda para a reconstituição do passado através da construção de narrativas memoriais, assim aproximando seus públicos de sua história e legitimando seu valor social. Desta maneira, acreditamos que o mesmo possa ser feito com a para a valorização da cultura, da história e memória locais, como a do município de São Borja.

\subsection{Os acervos, arquivos e suas fontes primordiais}

Os acervos são espaços de conservação de documentos e objetos de

4 A lei 8.159, de 8 de janeiro de 1991, define em seu artigo 12: "Os arquivos privados podem ser identificados pelo poder público com de interesse público e social, desde que sejam consideradas como conjuntos de fontes relevantes para a história e desenvolvimento científico nacional". 
interesse institucional, privado ou público (comunitário) principalmente para aqueles que usam essas documentações como objeto de estudos para, assim, gerar novos dados pertinentes para a sociedade, ou seja, acervo é um "conjunto de documentos que, independentemente da natureza ou do suporte, são reunidos por acúmulo ao longo das atividades de pessoas físicas ou jurídicas, públicas ou privadas" (CAMARGO; BELLOTTO, 1996, p.5).

Assim, existem alguns atributos que identificam os acervos, essas características dizem respeito ao seu recorte temático, que quer dizer a delimitação do assunto que esse acervo tem, outras características e sua organicidade: suas derivações das funções e/ou estruturas da entidade que o acumulou, sua indissociabilidade, e a outra particularidade é a unicidade: "qualidade pela qual os documentos de arquivo, a despeito de forma, espécie ou tipo, conservam caráter único em função de seu contexto de origem" (CAMARGO; BELLOTTO,1996, p.76).

Quando falamos em acervos, a principal característica é o acúmulo de informações, sendo assim denominamos que as pessoas que têm abundância de conhecimentos, experiências e histórias, são consideradas como potenciais fontes orais. De acordo com Fernandes (2011) há um certo questionamento com relação à credibilidade das fontes orais, especialmente nas motivações pessoais que podem afetar a fidedignidades do relato oral, mas "do ponto de vista institucional enfatizamos que esse princípio condutor vem garantindo que o programa mantenha a sua linha multidisciplinar, custodiando coleções produzidas por diferentes linhas de pensamentos e metodologia" (FERNANDES, 2011,p. 111).

Cada arquivo se baseia em seus princípios gerais para realizar a sua organização, processo esse que exige que os principais responsáveis pela instituição tenham o conhecimento aprofundado das documentações do arquivo e sobre a organização destes registros. Dessa maneira, nota-se a importância do conhecimento arquivístico, no qual usam os devidos conhecimentos para tal organização, para que deste modo possa ser usada tal documentação de uma forma lógica, clara e com maior facilidade de acesso, para isto norteia-se em dois princípios: 1) Princípio da proveniência: preceito que diz que os registros devem manter sua individualidade; 2) Princípio da ordem original: preceito que diz que os documentos têm que garantir sua preservação conforme ela é.

Posto isto, podemos salientar que conforme seus princípios cada arquivo acaba definindo sua natureza conforme suas atividades desempenhadas dentro dos acervos, pois as documentações estarão sujeitas a mudanças conforme suas atividades desempenhadas nos acervos. Decorrente disto forma-se a natureza do acervo, podendo assim englobar vários tipos de documentações.

Como exemplo, entre as principais fontes de informação aos acervos observam-se as seguintes: a) Audiovisual/ videoteca - vídeos, CD, fitas de vídeos, que contenham informações de interesse ao acervo; b)Bibliográfica - produções e estudos vinculados com assuntos do acervo; c) Cultura matéria l- objetos tridimensionais e documentos que tenham valores significativos para as instituições; d) Museológico - Objetos e documentos que tenham relevância pelo 
CULTURA E MEMÓRIA EM PERSPECTIVA:

seu caráter único e inovador, por isso sua importância; e) Fotográfico - fotos e registros relacionados com o assunto da instituição; f) Banco de depoimentos - registros conservados em áudios, vídeos, escritos ou outros documentos de pessoas, ligadas direta ou indiretamente ao acervo, fornecerão informações relevantes ao assunto; e g) Coleções -documentos que confirmam aspectos particulares relacionados com a matéria de importância do acervo.

Os acervos têm uma principal função que é acomodar esses documentos que são de grande relevância social, e para que essa função seja cumprida é necessário que esses documentos sejam preservados, sistematizados e acessíveis ao público, já que estamos falando de documentos e espaços públicos, sendo estes arquivos museus, bibliotecas e centros de documentação.

No estudo aqui apresentado, foca-se no caso dos acervos histórico-culturais existentes na cidade de São Borja, no extremo oeste do Rio Grande do Sul, onde se observa, ao mesmo tempo, a importância histórica dos arquivos e fontes documentais existentes nos diferentes espaços culturais mapeados. E, por outro lado, flagra-se o evidente descaso com o patrimônio público e a carência de políticas públicas voltadas à preservação e ao acesso público a tais fontes.

\section{Método de pesquisa}

O presente trabalho tem por objetivo expor as propostas do projeto de pesquisa "Memória Pública e Memória Cultural: um estudo histórico comunicacional", que pretendeu dar continuidade às pesquisas exploratória, bibliográfica e documental, iniciadas em 2018. Momento este em que foi elaborado um levantamento das políticas desenvolvidas no município de São Borja - RS, no tocante à cultura.

Nesse sentido a pesquisa buscou realizar análises em Atos, decretos e leis ordinárias municipais encontrados na biblioteca municipal, no acervo da cidade. O projeto atualmente visa integrar e compreender de maneira mais ampla a problemática da conservação da memória, especificamente da memória pública e cultural. A pesquisa se justifica a partir da concepção da dificuldade dos acessos aos respectivos documentos, visto que não existe uma devida conservação desse patrimônio, dificultando o acesso e o reconhecimento dessas informações (SANTOS; FERNANDES, 2020).

A pesquisa se desenvolve em três etapas, num primeiro momento através da pesquisa exploratória, visto que haverá coleta de dados primários e secundárias. Como método e técnicas o projeto conta com a colaboração de pesquisa bibliográfica e documental, visando compreender as políticas desenvolvidas pelo município, e naquela realizar fundamentações teóricas acerca do tema cultura, memória e preservação, a partir das discussões propostas por Lotman (1998) relativo a representações e significados em relação à cultura e memória. Nessa perspectiva, as fontes e informações coletadas através da etapa 1 estabelecem os fundamentos à reflexão sob a ótica comunicacional, que 
por consequência constituem a etapa 2 (dois), cuja finalidade é estabelecer os desafios e possibilidades para a conservação da memória pública e cultural, visando a promoção da memória e história no município.

Os resultados preliminares aqui apresentados dão conta de um levantamento exploratório inicial que permitem observar o panorama dos acervos histórico-culturais no município de São-Borja e a diversidade de fontes existentes. $E$, ao mesmo tempo, são percebidos os problemas de registro, conservação e acesso público aos documentos históricos que guardam a cultura e a memória da cidade, da região missioneira e de personalidades políticas brasileiras, como as dos ex-Presidentes da República Getúlio Vargas e João Goulart.

\section{Apresentação e discussão dos resultados}

4.1 Acervos histórico-culturais na cidade de São Borja-RS: levantamento inicial

O levantamento que apresentamos a seguir diz respeito à pesquisa exploratória realizada na cidade de São Borja, Rio Grande do Sul, cujo fim é identificar os acervos histórico-culturais existentes no município, a constituição de tais espaços, variedade de fontes existentes e condições de acesso às informações.

A cidade de São Borja situa-se no extremo Oeste do Rio Grande do Sul, é popularmente conhecida como "Terra dos Presidentes", lugar de nascimento e residência de dois ex-Presidentes da República, Getúlio Vargas (1930-1945 e 1951-1954) e João Goulart (1961-1964), além de berço das Missões Jesuítico-Guaranis brasileiras, por ter sido a primeira redução jesuítica no Brasil em 1682. Todos estes fatores já situariam a cidade em um lugar privilegiado na história brasileira, e atraíram nossa atenção para a pesquisa relacionada às práticas de preservação da memória do município e, especialmente, das fontes de informação históricas e culturais existentes, porém, muitas vezes desconhecidas ou mesmo desvalorizadas como patrimônio histórico-cultural material.

Nesse sentido, realizou-se, entre 2018 e 2020, um levantamento dos espaços histórico-culturais existentes na cidade de São Borja, detentores de acervos, arquivos e fontes de informação de importância histórica. Como resultado foram identificados seis (6) espaços ou acervos para a composição do estudo, sendo eles: 1) Museu Getúlio Vargas; 2) Casa Memorial João Goulart; 3) Museu Aparíccio Silva Rillo; 4) Museu Ergológico da Estância; 5) Acervo da Câmara Municipal de Vereadores e 6) Arquivo Público Municipal de São Borja. A seguir descreve-se brevemente cada um dos espaços identificados em nossa pesquisa.

O Museu Getúlio Vargas foi construído inicialmente como a casa do Ex-Presidente da República Federativa do Brasil, Getúlio Vargas, onde de fato assim foi quando era vivo. Conforme o IPHAE (Instituto do Patrimônio Histórico e Artístico do Estado) a casa foi edificada aproximadamente no ano de 1911, o prédio possui uma arquitetura com características mistas, no qual com o 
passar dos anos foram realizadas algumas modificações para sua preservação. O Museu conta como foi sua história, principalmente sua história na política, conforme as pesquisas realizadas encontramos no museu, roupas, cuias, com um acervo com mais de 1.500 livros, além de outros elementos pessoais, bem como de relatos de que é a parte do museu vivo que consiste em uma explicação por vídeo. O acervo completo conta com mais de 2.000 itens, que rememoram a trajetória da vida do estadista como fardas, objetos de decoração, peças do vestuário, ternos, fotos, móveis, livros e demais objetos de seu uso cotidiano. Cabe lembrar que outra parte dos pertences pessoais de Getúlio Vargas estão em um acervo no Palácio do Catete, no Rio de Janeiro, museu este que conta a história da memória da República.

O Memorial Casa João Goulart situa-se em um casarão histórico que data de 1927, localizada na cidade de São Borja na Avenida Presidente Vargas, $n^{\circ}$ 2.033. A casa pertenceu à família do ex-Presidente da República João Goulart (Jango) e foi cedida à Prefeitura Municipal de São Borja, responsável atualmente pela manutenção do espaço cultural. Tombada em 1991 como patrimônio histórico do município de São Borja, em 1994 é tombada como patrimônio histórico do Rio Grande do Sul (GERMOLIATO, 2019). Por meio de pesquisas iconográfica, documental e de um projeto expográfico, foram criados espaços expositivos em que narram a trajetória pessoal e política de João Goulart. O acervo, composto de fotos, objetos pessoais e móveis de família é dedicado à preservação da memória do ex-presidente Jango, retratando o espaço em que ele vivia com a família e dispondo de objetos que retratam as suas práticas cotidianas.

Junto à Biblioteca Municipal de São Borja é criado, no início da década de 70, o Museu Municipal, que com a Lei 2.559/1997 do município de São Borja passa a denominar-se Museu Apparício Silva Rillo, em homenagem ao poeta que residiu grande parte de sua vida na cidade. Tradicionalmente conhecido como "Museu Missioneiro" encontra-se nesse espaço cultural relíquias do período da redução de São Francisco de Borja, contando com o segundo maior acervo da arte Jesuítica Barroca do Brasil. O museu foi modificado em 2007 e possui as adaptações necessárias para conservar de forma adequada os objetos de valor histórico. Acredita-se que tais acervos sejam reservas das singularidades locais e são a principal motivação para implantação de mais centros de memórias, reconhecendo sua existência, propiciando uma reflexão sobre o passado, assim como a valorização diante da sociedade e a transmissão desses valores às gerações futuras.

O Museu Ergológico da Estância está localizado na cidade de São Borja-RS, foi fundado em 1982 pelo Grupo artístico-cultural amador "Os Anguras". Por conseguinte, a sede do museu está localizada junto à propriedade privada do referido grupo, mas conta também com o apoio e subvenções da Prefeitura Municipal de São Borja. O acervo museológico retrata o trabalho no campo, o estilo de vida nas estâncias, mostra como eram as residências, móveis, utensí- 
lios e ferramentas, além de abordar a cultura gaúcha-missioneira, ressaltando a rotina de trabalho e os hábitos culturais dos trabalhadores daquela época (ALMEIDA; THESING; VARGAS, 2018).

O acervo da Câmara Municipal de Vereadores está localizado junto à sua sede, na Rua Olinto Arami Silva, n. 1043, no centro da cidade de São Borja, e conta com documentos referentes às legislações municipais, além da parte das Atas das sessões da Câmara. O espaço, um cubículo embaixo de uma escadaria, não se mostra adequado para a salvaguarda e conservação de documentação de tamanha importância. $\mathrm{O}$ arquivo tampouco foi sistematizado ou organizado e apenas parte do acervo documental da Câmara foi digitalizado, no entanto, não se encontra disponível virtualmente para acesso à comunidade. Nesse caso, a consulta aos documentos realiza-se mediante solicitação prévia à Câmara de Vereadores.

De acordo com a pesquisa realizada por Padilha $(2019$, p.133) o arquivo municipal de São Borja foi alocado em diferentes espaços, desde 2005, passando a partir de 2010 a localizar-se na antiga Estação Férrea da cidade, um prédio histórico e preservado como patrimônio municipal" "no local, encontram-se antigas atas, registros de nascimento e falecimento, escrituras de casas e alguns manuscritos do período imperial". Atualmente, o arquivo é coordenado pelo servidor público municipal Clóvis Benevenuto que, apesar da precariedade do espaço e das condições de alocação e conservação do acervo, busca organizar e classificar os documentos, auxiliando pesquisadores e a comunidade em geral na busca por informações e pesquisas acadêmicas.

A partir do diagnóstico inicial dos acervos, observou-se a existência de documentos em bom estado no Museu João Goulart, contudo, nem todos estão devidamente catalogados, dificultando a pesquisa e acesso público. Já no museu Getúlio Vargas houve uma dificuldade para poder ter acesso às informações, pois não foi concedido acesso, tampouco souberam esclarecer sobre informações do acervo, mas no Acervo Municipal foi possível realizar uma pesquisa e, com isso, notamos que o acervo está adequadamente organizado mas não são tomados os cuidados devidamente necessários com os documentos.

Em um dos postulados de luri Lotman, com relação à memória na ótica da culturologia, o autor afirma que "desde el punto de vista de la semiótica, la cultura es una inteligencia colectiva y una memoria colectiva" (LOTMAN, 1996, p. 109). Nesse caso, assume-se que a cultura permanece, mantém-se igual ao longo do tempo, mas o que varia são as interpretações em torno dela que se atualizam e reatualizam especialmente através de textos. Essa relação temporal, mnemônica da cultura que é ativada pela recepção e apropriação dos objetos culturais pelos sujeitos, torna-se um dos diferenciais da teoria semiótica lotmaniana e que permite investigar a cultura tanto por meio de uma ótica histórica - sincrônica ou diacronicamente, a partir dos textos e documentos

\footnotetext{
5 Imóvel tombado pela Lei Municipal n Lei 4.464, de 2011, cujo texto é transcrito a seguir a partir de informações coletadas no contexto do Projeto de Pesquisa Resgate e preservação da memória cultural de São Borja sob o prisma da comunicação e das relações públicas, realizado no ano de 2018: Lei n.4.464/ 2011 - Tomba, com vista à Preservação do Patrimônio Histórico e Cultural do Município de São Borja o imóvel onde funcionava a Estação Férrea e dá outras providências".
} 
CULTURA E MEMÓRIA EM PERSPECTIVA:

que guardam esta memória - como comunicacional, entendendo a cultura enquanto conjunto de informações, organizadas e sistematizadas, que revelam a dinâmica de uma sociedade e que se revelam no trabalho interpretativo, na operação semiótica de atribuição de sentido aos objetos culturais.

Ou seja, ao observar a problemática cultural pela ótica da Escola de Tártu, base conceitual da nossa pesquisa, percebemos que o próprio sentido de cultura está relacionado às dinâmicas coletivas de interação, circulação e conservação de práticas, ritos, mas também de textos e documentos, situando nesse ponto a memória e especialmente a preservação memorial (AMORIM; SANTOS, 2020). Ao serem preservados em acervos públicos, os textos com história ou mitos não só geram novos significados, como também contribuem para a memória cultural, admitindo assim uma capacidade semiótica, com capacidade de acumulação e reserva de memória.

Assim, a pesquisa revela o descaso com os acervos histórico-culturais existentes no município de São Borja, em especial os arquivos da Câmara Municipal de Vereadores, da Casa Memorial João Goulart e do Arquivo Público Municipal, espaços que reúnem documentos e fontes de interesse inestimáveis, mas que ainda carecem de estratégias de preservação estruturadas. O cenário aqui apresentado demonstra a fragilidade do sistema municipal, em relação às políticas públicas de preservação do patrimônio e da memória pública e cultural, bem como a dificuldade no acesso a informações contidas nesses espaços, revelando enormes desafios, mas também inúmeras possibilidades no desenvolvimento de pesquisas e iniciativas que contribuam à conservação da memória pública e cultural no município.

\section{Considerações finais}

Após estudos iniciados em 2018, com a finalidade de investigar a cultura e da memória no município de São Borja, especialmente as políticas culturais municipais e as estratégias de preservação da cultura e da memória de objetos e documentos de valor históricos, observou-se, em primeiro lugar, a dificuldade em localizar e ter acesso às informações relativas às práticas, ações e legislações voltadas à cultura, revelando um notório problema de transparência pública, e, em segundo lugar, identificou-se a existência de diferentes fontes de informação histórico-culturais na cidade - acervos ou arquivos de acesso público - mas muitas vezes armazenados, alocados de maneira inadequada, denunciando a ausência de políticas de conservação documental e arquivística. Nesse trabalho, dedicamo-nos a observar esse segundo aspecto, que diz respeito aos acervos e arquivos existentes no município e a problemática em torno da sua preservação.

Como fundamento da pesquisa, evidenciamos a contribuição da Escola de Tártu-Moscou para os estudos dedicados à memória e à cultura, na medida em que aborda tais conceitos como mecanismos contra o esquecimento. Para além disso, ao tratar cultura como informações codificadas em textos e nesse sentido, compreendemos que os textos são meios facilitadores ao acesso de 
informações e para gerar novos sentidos dentro de uma determinada cultura. Logo, depreendemos que se o que difere o ser humano dos demais animais são as habilidades de dar sentidos às coisas, e que a cultura faz parte desse sistema de signos, logo é fundamental à comunicação e, ao ser estruturada em texto e preservada, pode facilitar o acesso às gerações futuras, ao entendimento do contexto social e cultural no qual estão inseridas.

Ao compartilhar nossas reflexões, acabamos por reforçar as dificuldades encontradas no decorrer das pesquisas, no que tange à falta de entendimento do que seja memória e da importância de todo e qualquer fragmento, objeto, vestígio que a constitui, formando o patrimônio cultural de uma comunidade. Nesse sentido, ao trazermos a semiótica da cultura para dentro de nossas reflexões, conseguimos compreender de maneira mais teórica a importância da preservação dos acervos municipais da cidade de São Borja - RS.

Em relação à preservação dos acervos, o desinteresse por parte das gestões municipais, a rigor, implicam diretamente a desvalorização da própria história, pois os espaços histórico-culturais levantados na pesquisa constituem verdadeiros lugares de memória (NORA,1984) e acabam por cair em uma acentuada decadência, por falta de iniciativas formais, advindas do poder público, em prol de salvaguardar as identidade, as histórias, que se configuram como elementos formadores e constitutivos da memória local.

A partir da pesquisa realizada nos acervos públicos de São Borja-RS, foi possível fazer um breve levantamento dos acervos existentes, identificando as problemáticas evidentes relacionadas à preservação documental, o registro de documentos históricos e as formas de acesso público a tais acervos. Em alguns casos percebemos pequenos avanços na organização do material arquivístico, como no Museu Getúlio Vargas, que dispõe de uma sala específica onde são acondicionados os documentos que compõem seu acervo, no entanto, o ambiente não é climatizado, o acervo não se encontra categorizado e sistematizado, e o acesso ao público, para consulta ou pesquisas, ainda é limitado.

Portanto, preservar a memória cultural é relevante para que gerações futuras entendam e conheçam suas origens e, para além disso, a partir de textos possam (re)significar novos signos a partir das interpretações. Para tal, na atualidade, além dos acervos físicos e patrimônios culturais, dispõem-se ainda da digitalização de documentos, disponibilizando o patrimônio documental no ambiente virtual, e atualizando, assim, as alternativas de preservação memoriais, sem deixar de lado o tradicional, mas auxiliando na solução das problemáticas apontadas.

Como resultado, a pesquisa, reflexão e promoção da memória cultural do município de São Borj lançam luz sobre campo da memória pública ao assinalar perspectivas para a sua salvaguarda e preservação. Para tanto, o presente trabalho alinha-se a uma possível forma de educar, questionar e chamar a atenção para a importância em salvaguardar a cultura local, porém, prevemos uma longa caminhada para evidenciar a importância dos acervos existentes na cidade de São Borja, de modo que não caiam na invisibilidade. 
CULTURA E MEMÓRIA EM PERSPECTIVA:

REFLEXÕES SOBRE OS ACERVOS HISTÓRICO-CULTURAIS NO MUNICÍPIO DE SÃO BORJA-RS

\section{Referências}

ALMEIDA, Juniele R.; ROVAI, Marta G. O. Introdução à história pública. São Paulo: Letra e Voz, 2011.

ALMEIDA, Magalia. G. S.; THESING, Nelson José; VARGAS, Melissa. W. Desenvolvimento do Território: Marketing de Cidades. Revista científica multidisciplinar núcleo do conhecimento, v. 03, p. 37-50, 2018. Disponível em: <https://www.nucleodoconhecimento.com.br/marketing/marketing-de-cidades> Acesso em: 03 jul 2020.

AMORIM, Catarina M. S.; SANTOS, Larissa C. A Escola de Tartú-Moscou: contribuições aos estudos sobre cultura e memória. Revista Temática, v.18 n.9, 2020 (no prelo).

BELLOTTO, Heloísa Liberalli. Arquivística: objetos, princípios e rumos. São Paulo: Associação de Arquivistas de São Paulo, 2002

BEZERRA, Eutrópio P; OLIVEIRA, Danielle A.Preservação da memória: técnicas e tecnologias alternativas para a salvaguarda de acervos documentais. In: Anais... Encontro Nacional de Pesquisa em Ciência da Informação, v.14, 2013. Disponível em: < https://www.brapci.inf.br/index.php/article/ view/0000013832/2cc60270cbe878fc53c2da36645bdccc> Acesso em: 02 jul 2020.

COSTA, L. T; VITORIANO, M. C. C. P. Composição de acervos em centros de memória institucional. Anais ...CONGRESSO NACIONAL DE ARQUIVOLOGIA - CNA, 8., 2018, João Pessoa.Revista Analisando em Ciência da Informação - RACIn, João Pessoa, v. 6, n. especial, p. 526-546, out.2018. Disponível em: <http://racin.arquivologiauepb.com.br/edicoes/v6_nesp> Acesso em: 05 out 2019.

CAMARGO, Ana Maria; GOULART Silvana. Centros de memória: uma proposta de definição. Coleções Sesc Culturas. São Paulo: Edições Sesc 2015

CAMARgo, Ana Maria A. BELlOTTO, Heloísa Liberalli(Coord.) Dicionário de Terminologia Arquivística. São Paulo: Associação dos Arquivistas Brasileiros - Núcleo Regional de São Paulo: Secretaria de Estado da Cultura, 1996.

FERREIRA, Jerusa P. Cultura é memória. São Paulo, SP: Revista Usp, 1994/95.

GEERTZ, Clifford. A interpretação das culturas. Rio de Janeiro: Ed. 1989.

GERMOLIATO, Gabriel S. ${ }^{100}$ Jango: comunicação, memória, museu e patrimônio.2019. 67fl. Trabalho de Conclusão de Curso (Bacharelado em Relações Públicas), Universidade Federal do Pampa -UNIPAMPA, 2019.

FERNANDES, S. S. Fontes orais: Perspectivas para o tratamento em centros de documentação e arquivos.In: ALMEIDA, Juniele R.; ROVAI, Marta G. O. Introdução à história pública. São Paulo: Letra e Voz, 2011.

GOULART, S. Patrimônio documental e história institucional. São Paulo: Associação dos Arquivistas de São Paulo, 2002.

IPHAE. Instituto do Patrimônio Histórico e Artístico do Estado (Iphae). Disponível em: <http://www.iphae.rs.gov.br/ Main.php?do=BensTombadosDetalhesAc\&item=15643>. Acesso em: 15, Julho de 2020.

LAURETTI, Carolina Filardo. Centros de memória e arquivos históricos: semelhanças e Diferenças. $2011,62 \mathrm{f}$. Monografia (Graduação em Biblioteconomia e Documentação) ECA-USP, São Paulo, 2011.

LOTMAN, lúri M. La semiosfera II. Semiótica de la cultura, del texto, de la conducta y del espacio. Frónesis Cátedra/ Universitat de València, 1998.

MACHADO, Irene. Cultura em campo semiótico. São Paulo, SP: Revista Usp, 2010

NORA, Pierre. Les lieux de mémoire. Paris : Gallimard, 1984.

PADILHA, Eufrásia C. P. Análise das políticas públicas culturais na cidade de São Borja - Rio Grande do Sul de 2005-2015: avanços e retrocessos. 2019. 197 p. Dissertação (Mestrado Profissional em Políticas Públicas). São Borja, UNIPAMPA, 2019. Disponível em: <http://dspace.unipampa.edu.br/jspui/bitstream/riu/3976/1/ Eufr\%C3\%A1sia\%20Concei\%C3\%A7\%C3\%A30\%20Ponce\%20Padilha\%202019.pdf> Acesso em: 10 jun. 2020

PAES, Marilena Leite. Arquivo: teoria e prática. 3.ed. rev. ampl. Rio de Janeiro: Editora FGV, 2004. 
SANTOS, L. C; BONITO, M. O texto face ao digital: comunicação apropriação e memória em perspectiva. In: FEIL, G. S; OLIVEIRA, M. R; FEITOSA, S. Texto. Assis: Triunfal Gráfica e Editora, 2019. p.229 - 241.

SANTOS, Larissa C.; FERNANDES, Fabio F. Desafios à preservação da memória cultural no Brasil: um estudo no município de São Borja. Revista Brasileira de História da Mídia-RBHM, v.9, n. 1, jan./jun 2020, p. 219236. Disponível em: <https://revistas.ufpi.br/index.php/rbhm/article/view/8566> Acesso em: 24 jul. 2020.

THOMPSON, J. B. Ideologia e cultura moderna. Petrópolis: Vozes, 1985.

TOTINI, Beth; GAGETE, Elida. Memória Empresarial, uma análise de sua evolução. In: NASSAR, Paulo (org) Memória de Empresas: história e comunicação de mãos dadas a construir o futuro das organizações. São Paulo: Aberje, 2004. p.130

VELHO, Ana Paula Machado. A semiótica da cultura: apontamentos para uma metodologia de análise da comunicação. Revista de Estudos da Comunicação, v. 10, n. 23, 2009. 